\title{
Timber supply implications of natural disturbance management
}

\author{
by Glen W. Armstrong ${ }^{1}$, Steven G. Cumming ${ }^{2}$ and Wiktor L. Adamowicz ${ }^{3}$
}

The timber supply implications of applying an interpretation of the natural disturbance model (NDM) of forest management were examined, using a computer model simulating forest growth and harvest. Under the natural disturbance model, much less timber was available for harvest than under maximum sustained timber yield management. Several questions relating to implementation of the natural disturbance model of management are raised with the intent of stimulating some discussion.
Les implications sur l'approvisionnement en bois suite a l'implantation de l'interpretation d'un modele de perturbation naturelle (NDM) a titre d'amenagement forestier ont ete etudiees, au moyen d'un modele informatique simulant la croissance forestiere et la recolte. Selon le modele de perturbation naturelle, il y a beaucoup moins de bois disponible pour la recolte que selon un amenagement maximal soutenu de rendement en matiere ligneuse. Plusieurs questions se rapportant a l'implantation d'un modele de perturbation naturelle sont soulevees dans le but de stimuler la discussion.

\section{Introduction}

The natural disturbance model (NDM) of forest management (Hunter 1993) is the basis of many of the ecosystem management approaches being proposed for the boreal forest (Haila et al. 1994, Gauthier et al. 1996). The central assumption behind this model is that timber harvest practices designed to mimic natural disturbances will help achieve the goal of a sustainable ecosystem while providing timber and other goods and services. Hunter identifies three properties of natural disturbance that could be mimicked by harvesting: spatial pattern, residual material, and rates of disturbance. Hunter focuses on spatial pattern, Lee et al. (1997) discuss residual material, and this paper focuses on rates of disturbance.

Most of the discussion of NDM management in the boreal forest has focused on emulating the effects of stand-replacing wildfire, possibly because

1) wildfire is the most important (or at least, most obvious) non-anthropogenic agent of change in the boreal forest (Johnson 1992),

2) to the degree that fire suppression efforts are successful, timber harvest can be compensatory to wildfire, and

3) emulation of a stand-replacing fire may allow for harvest techniques similar to those used in clearcut harvesting.

Natural disturbances operate over a continuum of spatial scales - the stand (patch or block scale) and the forest (estate or landscape scale) are particularly relevant to forest management decisions. Stand level considerations will affect cutblock layout and the amount of timber removed from a particular site. For example, one would expect that maintenance of residual structure in a cutblock would reduce the harvested yield (measured in $\mathrm{m}^{3} \mathrm{ha}^{-1}$ ). Forest level considerations will affect

\footnotetext{
${ }^{1}$ Department of Rural Economy, University of Alberta, Edmonton AB, T6G 2H1; email: glen.w.armstrong@ualberta.ca

${ }^{2}$ Department of Renewable Resources, University of Alberta, Edmonton AB, T6G 2H1; email: steve.cumming@ualberta.ca

${ }^{3}$ Department of Rural Economy, University of Alberta, Edmonton AB, T6G 2H1; email: vic.adamowicz@ualberta.ca
}

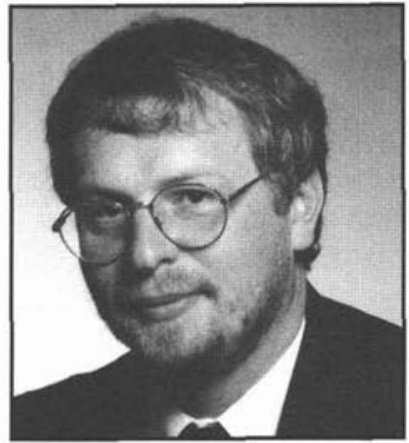

Glen W. Armstrong

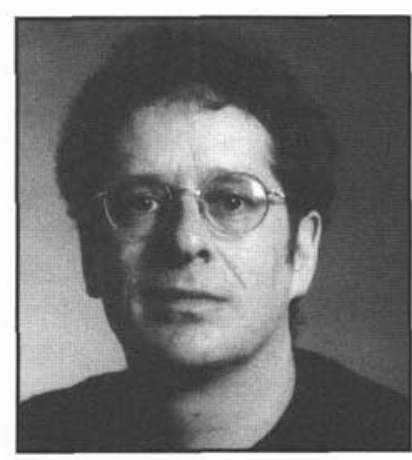

Steven G. Cumming the size and spatial distribution of harvested areas, the distribution of cover types and age classes over the landscape, the type of stands scheduled for harvest, and the rates at which they are harvested. These harvest-scheduling considerations are very important as they relate directly to the allowable cut for an area and the distribution of this cut in space and time.

One strategy for setting tim-

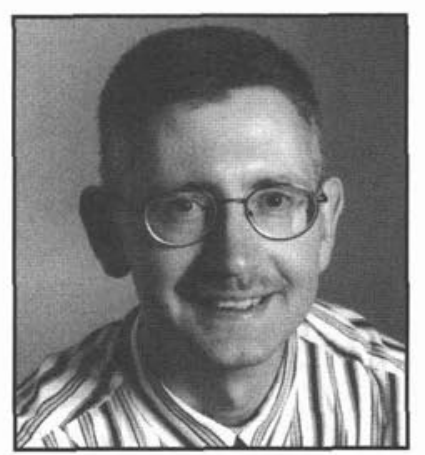

Wiktor L. Adamowicz ber harvest levels under a natural disturbance model is to dictate that the average annual area disturbed under management should equal the average annu$\mathrm{al}$ area disturbed under natural conditions. This presupposes that forest protection activities have had the effect of reducing the annual area disturbed. The allowable annual harvest area is then the difference between the average area disturbed under natural conditions and the average area disturbed given the level of forest protection. In order to use this strategy, one must be able to determine average annual disturbance rates with and without fire suppression. 


\begin{tabular}{|c|c|c|c|c|c|c|c|c|c|c|}
\hline \multirow[b]{2}{*}{ Age(yrs.) } & \multicolumn{10}{|c|}{ Conifer Content (percent) } \\
\hline & 0-10 & $11-20$ & 21-30 & $31-40$ & $41-50$ & $51-60$ & $61-70$ & $71-80$ & $81-90$ & $91-100$ \\
\hline $0-4$ & 9521 & 1065 & 0 & 750 & 290 & 37 & 702 & 41 & 647 & 6697 \\
\hline $5-14$ & 60 & 0 & 0 & 254 & 10 & 0 & 43 & 4 & 0 & 256 \\
\hline $15-24$ & 2161 & 225 & 34 & 199 & 62 & 23 & 506 & 99 & 112 & 2104 \\
\hline $25-34$ & 8417 & 2730 & 182 & 1648 & 123 & 118 & 1389 & 73 & 1238 & 5521 \\
\hline $35-44$ & 14199 & 5412 & 264 & 3877 & 292 & 600 & 1728 & 638 & 1580 & 15775 \\
\hline $45-54$ & 37855 & 16309 & 239 & 10554 & 1581 & 823 & 8127 & 879 & 6813 & 23082 \\
\hline $55-64$ & 40285 & 18546 & 612 & 12907 & 1681 & 2258 & 10848 & 2099 & 8249 & 34851 \\
\hline $65-74$ & 36096 & 20151 & 128 & 8227 & 1601 & 666 & 3486 & 460 & 4072 & 11185 \\
\hline $75-84$ & 29269 & 12088 & 143 & 7326 & 714 & 1563 & 3626 & 526 & 3210 & 12597 \\
\hline $85-94$ & 13347 & 9369 & 366 & 5733 & 1167 & 450 & 3780 & 835 & 3103 & 12583 \\
\hline $95-104$ & 12798 & 15648 & 896 & 12299 & 870 & 593 & 7363 & 1004 & 4536 & 27612 \\
\hline $105-114$ & 3723 & 3391 & 437 & 5142 & 483 & 355 & 5444 & 871 & 4253 & 12076 \\
\hline $115-124$ & 2931 & 1985 & 611 & 4910 & 576 & 645 & 7888 & 1220 & 2689 & 13796 \\
\hline $125-134$ & 1431 & 1110 & 185 & 2689 & 477 & 189 & 7582 & 662 & 6014 & 12221 \\
\hline $135-144$ & 2032 & 1217 & 926 & 3653 & 900 & 1682 & 6974 & 2819 & 6319 & 14464 \\
\hline $145-154$ & 144 & 174 & 30 & 207 & 39 & 182 & 1127 & 681 & 1386 & 3038 \\
\hline $155-164$ & 343 & 310 & 49 & 607 & 125 & 117 & 1378 & 787 & 1431 & 2036 \\
\hline $165-174$ & 6 & 36 & 9 & 64 & 0 & 0 & 166 & 29 & 158 & 562 \\
\hline $175-184$ & 217 & 0 & 0 & 5 & 0 & 7 & 173 & 0 & 31 & 119 \\
\hline $184-194$ & 191 & 38 & 0 & 5 & 0 & 0 & 14 & 28 & 28 & 142 \\
\hline $195+$ & 0 & 0 & 0 & 3 & 0 & 0 & 0 & 2 & 10 & 46 \\
\hline
\end{tabular}

Alberta-Pacific Forest Industries Inc. (APFI) has proposed to use this strategy for determining annual harvest levels for their Forest Management Agreement Area in northeastern Alberta. They plan research to "determine the differences in disturbance rates across the FMA, so that harvest rates and methods can emulate the disturbance rate for each 'disturbance rate' zone" (Alberta-Pacific Forest Industries Inc., undated). This approach to allowable cut determination is very different from the usual methods used in Alberta. In essence, the "natural rate" approach assumes that the natural rate of disturbance can be determined for a forest area, and that this rate of disturbance should be applied to the managed forest. In other words, the annual area disturbed (harvested and burned) under management should equal the annual area disturbed (burned) under natural conditions. To date, no examination has been made on the potential effects on timber supply resulting from the implementation of this approach.

Van Wagner (1983) presented a forest level simulation model incorporating a natural disturbance process similar to that modelled in this paper, and timber harvest. The purpose of his model was to examine the effects of different annual rates of burn on the long-term equilibrium timber supply of a forest. Reed and Errico (1986) examined a similar problem using an optimization framework. In both these papers, the objective was to determine the appropriate level of harvest given that a specified proportion of the forest was expected to burn each year.

Our model is less ambitious and serves a different purpose. We develop a simple simulation model of forest growth and disturbance. It is used to compare the areas and volumes disturbed under different estimates of the natural disturbance rate with results from a sustained timber yield model (without disturbance). The areas and volumes disturbed under the natural disturbance scenarios can be usefully thought of as defining the upper limits to areas and volumes harvested under the AFPI approach to natural disturbance management. The sustained yield scenario is intended to represent the status quo for harvest level determination in Alberta. We will show that the schedules of harvest area and volume for the different scenarios are strikingly different. The analysis presented here is not a methodological advance, but is an example of how a simple model can be a useful tool for evaluating the effects of a change in forest policy or practices. The results presented here provide a starting point for discussion of the relationship between the natural disturbance model of forest management and timber harvest levels.

\section{Model Development}

The model is a straightforward representation of forest growth and disturbance. The initial forest is represented as a matrix of productive area indexed by age and conifer content. Each year, a proportion of the area is disturbed and regenerates according to our regeneration assumptions. The portion of the area that is not disturbed increases in age by one year. A proportion of the area in each conifer content class moves to the next highest conifer content class. This sequence is repeated for each year in the specified simulation period. The inputs to the model used here consist of a set of forest inventory data, timber yield tables, succession and regeneration assumptions, and annual disturbance probabilities. These are described in this section.

We obtained forest inventory data for a portion of the boreal forest in northeastern Alberta covering 300 townships (15 townships north by 20 townships east), or approximately $2.8 \times 10^{6} \mathrm{ha}$. The stand listings include a description of the forest cover type including species composition, stand age, and gross stand area as interpreted from aerial photographs. As part of a timber supply analysis for the area, the net productive land base of the study area was determined. Areas considered unmerchantable (including wetlands, swamps, and bogs), inoperable, or as part of reserves or buffers are excluded from the net productive land base. The net land base of the study area consists of $785042 \mathrm{ha}$. We describe the forest in terms of the area in ten-year-wide age classes and ten-percent-wide 


\begin{tabular}{|c|c|c|c|c|c|c|c|c|c|c|}
\hline \multirow[b]{2}{*}{ Age(yrs.) } & \multicolumn{10}{|c|}{ Conifer Content (percent) } \\
\hline & $0-10$ & $11-20$ & $21-30$ & $31-40$ & $41-50$ & $51-60$ & $61-70$ & $71-80$ & $81-90$ & $91-100$ \\
\hline 0 & 0 & 0 & 0 & 0 & 0 & 0 & 0 & 0 & 0 & 0 \\
\hline 10 & 0 & 0 & 0 & 0 & 0 & 0 & 0 & 0 & 0 & 0 \\
\hline 20 & 0 & 0 & 0 & 0 & 0 & 0 & 0 & 0 & 0 & 0 \\
\hline 30 & 0 & 0 & 0 & 0 & 0 & 0 & 0 & 0 & 0 & 0 \\
\hline 40 & 0 & 0 & 0 & 0 & 0 & 0 & 0 & 0 & 0 & 0 \\
\hline 50 & 0 & 0 & 0 & 0 & 0 & 0 & 0 & 1 & 1 & 1 \\
\hline 60 & 0 & 0 & 0 & 0 & 0 & 0 & 13 & 25 & 38 & 51 \\
\hline 70 & 0 & 7 & 14 & 21 & 27 & 34 & 50 & 66 & 82 & 98 \\
\hline 80 & 0 & 15 & 30 & 45 & 60 & 75 & 92 & 109 & 125 & 142 \\
\hline 90 & 0 & 22 & 45 & 67 & 90 & 112 & 130 & 147 & 165 & 182 \\
\hline 100 & 0 & 29 & 58 & 87 & 116 & 145 & 164 & 182 & 201 & 219 \\
\hline 110 & 0 & 35 & 70 & 104 & 139 & 174 & 194 & 213 & 233 & 252 \\
\hline 120 & 0 & 40 & 80 & 120 & 160 & 200 & 220 & 241 & 261 & 282 \\
\hline 130 & 0 & 45 & 89 & 134 & 178 & 223 & 244 & 265 & 287 & 308 \\
\hline 140 & 0 & 49 & 97 & 146 & 195 & 243 & 265 & 287 & 310 & 332 \\
\hline 150 & 0 & 52 & 104 & 157 & 209 & 261 & 284 & 307 & 330 & 353 \\
\hline 160 & 0 & 55 & 111 & 166 & 222 & 277 & 301 & 324 & 348 & 371 \\
\hline 170 & 0 & 58 & 117 & 175 & 233 & 292 & 316 & 340 & 364 & 388 \\
\hline 180 & 0 & 61 & 122 & 183 & 244 & 305 & 329 & 354 & 379 & 403 \\
\hline 190 & 0 & 63 & 127 & 190 & 254 & 317 & 342 & 368 & 393 & 418 \\
\hline 200 & 0 & 66 & 132 & 198 & 264 & 330 & 356 & 382 & 407 & 433 \\
\hline
\end{tabular}

Table 3. Hardwood volumes $\left(\mathrm{m}^{3} \mathrm{ha}^{-1}\right)$ by age and conifer content

\begin{tabular}{|c|c|c|c|c|c|c|c|c|c|c|}
\hline \multirow[b]{2}{*}{ Age(yrs.) } & \multicolumn{10}{|c|}{ Conifer Content (percent) } \\
\hline & $0-10$ & $11-20$ & $21-30$ & $31-40$ & $41-50$ & $51-60$ & $61-70$ & $71-80$ & $81-90$ & $91-100$ \\
\hline 0 & 0 & 0 & 0 & 0 & 0 & 0 & 0 & 0 & 0 & 0 \\
\hline 10 & 0 & 0 & 0 & 0 & 0 & 0 & 0 & 0 & 0 & 0 \\
\hline 20 & 0 & 0 & 0 & 0 & 0 & 0 & 0 & 0 & 0 & 0 \\
\hline 30 & 0 & 0 & 0 & 0 & 0 & 0 & 0 & 0 & 0 & 0 \\
\hline 40 & 43 & 32 & 21 & 11 & 0 & 0 & 0 & 0 & 0 & 0 \\
\hline 50 & 99 & 80 & 61 & 42 & 23 & 18 & 14 & 9 & 5 & 0 \\
\hline 60 & 144 & 120 & 96 & 72 & 48 & 39 & 29 & 19 & 10 & 0 \\
\hline 70 & 180 & 153 & 127 & 100 & 73 & 59 & 44 & 29 & 15 & 0 \\
\hline 80 & 209 & 181 & 153 & 124 & 96 & 77 & 58 & 38 & 19 & 0 \\
\hline 90 & 233 & 204 & 174 & 145 & 116 & 93 & 69 & 46 & 23 & 0 \\
\hline 100 & 253 & 222 & 192 & 162 & 132 & 105 & 79 & 53 & 26 & 0 \\
\hline 110 & 269 & 238 & 207 & 176 & 145 & 116 & 87 & 58 & 29 & 0 \\
\hline 120 & 283 & 251 & 219 & 187 & 155 & 124 & 93 & 62 & 31 & 0 \\
\hline 130 & 295 & 262 & 229 & 196 & 163 & 130 & 98 & 65 & 33 & 0 \\
\hline 140 & 306 & 271 & 237 & 203 & 168 & 135 & 101 & 67 & 34 & 0 \\
\hline 150 & 315 & 279 & 244 & 208 & 173 & 138 & 104 & 69 & 35 & 0 \\
\hline 160 & 322 & 286 & 249 & 213 & 176 & 141 & 106 & 70 & 35 & 0 \\
\hline 170 & 329 & 292 & 254 & 216 & 178 & 142 & 107 & 71 & 36 & 0 \\
\hline 180 & 336 & 297 & 258 & 219 & 180 & 144 & 108 & 72 & 36 & 0 \\
\hline 190 & 341 & 301 & 261 & 220 & 180 & 144 & 108 & 72 & 36 & 0 \\
\hline 200 & 347 & 305 & 264 & 222 & 180 & 144 & 108 & 72 & 36 & 0 \\
\hline
\end{tabular}

conifer content classes. Conifer content classes are used here because stand inflammability is assumed to be related to conifer content, and they provide us with a way of tracking forest succession. The distribution of the inventory by age class and conifer content as of 1996 is presented in detail in Table 1.

Forest growth is modelled through the application of softwood and hardwood yield tables. The yield tables used here were derived by Joy (1995) from the Alberta Phase 3 white spruce, mixedwood, and hardwood yield tables (Alberta Forest Service 1985) calculated to the $13+/ 7 \mathrm{~cm}$ utilization standard. The softwood and hardwood yield tables used here are presented in Tables 2 and 3.

The succession model used here was developed by Cumming et al. (1995). They estimated a simple linear relationship between the photo-interpreted white spruce content of inventoried stands and the photo-interpreted age. Based on this rela- tionship, the annual percentage increase in white spruce content of stands is estimated to be $0.37 \%$. In the application used here, $3.7 \%$ of the area in each conifer content class moves to the next highest content class each year of the simulation.

Cumming (1997) also developed the regeneration model used here. The model assigns an age of zero to disturbed stands and allocates the area proportionately to conifer content classes using the proportions shown in Table 4. This empirical distribution was developed by examining the conifer content of stands originating in the 1960s and growing them backwards to age zero using the succession model described above. Using this model the probability of initial conifer content is independent of the conifer content of existing stands or management prescription.

We compare four different representations of disturbance regimes in this paper. The sustained yield regime (scenario SY) is intended to represent sustained yield management as cur- 


\begin{tabular}{lc}
\hline $\begin{array}{l}\text { Table 4. Proportion of disturbed stands regenerating to each conifer } \\
\text { content class }\end{array}$ \\
\hline Conifer Content & Proportion \\
\hline $0-10$ & 0.5500 \\
$11-20$ & 0.1738 \\
$21-30$ & 0.1018 \\
$31-40$ & 0.0125 \\
$41-50$ & 0.0739 \\
$51-60$ & 0.0134 \\
$61-70$ & 0.0233 \\
$71-80$ & 0.0486 \\
$81-90$ & 0.0028 \\
$91-100$ & 0.0000 \\
\hline
\end{tabular}

rently practised in Alberta. Murphy (1985) estimates the average annual pre-suppression disturbance rate for northern Alberta to be approximately two percent: we represent this regime as scenario M2. Cumming (1997), using different methods, estimates conifer content-specific disturbance rates for the region. His average annual disturbance rate is less than $0.5 \%$ : we represent this as scenario $\mathrm{C} 1$. For comparative purposes, we also develop a scenario using Murphy's model with a one percent annual disturbance rate (scenario M1).

We refer to areas and volumes disturbed rather than harvested or burnt. The area disturbed in any particular year will be equal to the sum of the areas burnt and harvested, because fire suppression will never be completely effective. This relates directly back to the idea that if timber harvest is to be compensatory to wildfire, fire suppression must be effective enough to reduce the disturbance rate.

Comparing the Murphy and Cumming regimes (M2, M1, and $\mathrm{C} 1$ ) to the sustained yield regime (SY) will provide some information on the timber supply implications of implementing a harvest scheduling system based on natural disturbance rates. Comparing the Murphy and Cumming regimes to each other may also be informative in that it provides a comparison of two independent estimates of the natural disturbance regime for the study area.

The disturbance schedule for sustained yield management (Scenario SY) was developed using a variant of the area-volume check (Davis 1966) developed by one of the authors (Armstrong). A standard area-volume check takes as input a table of forest area by age class and a yield table. Through an iterative procedure it finds the even-flow level of harvest which will result in the entire forest area being cut over exactly during a specified rotation period. This model rations out "surplus" old-growth volume over the rotation period.

Our variant of the area-volume check allows for the multiple yield tables and succession assumptions required by the growth models used in the NDM representation described below. We also allow for land base discrimination. Stands are classed as part of the hardwood land base if the conifer content is $50 \%$ or less; otherwise they are part of the softwood land base. In hardwood stands, even flow of hardwood volume is required; softwood volume is treated as incidental. The opposite applies to softwood stands. We chose to analyze a rotation of 100 years. This scenario is intended to represent harvest levels under the sustained yield management model as currently applied in Alberta.

The interpretation of NDM management examined here requires that the selection of stands for harvest should approximate nature's "selection" of stands for stand-replacing fires.

\begin{tabular}{lccc}
\hline \multicolumn{3}{c}{ Table 5. Mean disturbance rates based by conifer content class } \\
\hline \multirow{3}{*}{ Conifer Content } & Average & Background & Event \\
\hline$<10$ & 0.0027 & 0.00174 & 0.0104 \\
$10-20$ & 0.0027 & 0.00174 & 0.0121 \\
$20-30$ & 0.0027 & 0.0017 & 0.0139 \\
$30-40$ & 0.0027 & 0.0017 & 0.0156 \\
$40-50$ & 0.003 & 0.0017 & 0.0173 \\
$50-60$ & 0.003 & 0.0017 & 0.0211 \\
$60-70$ & 0.003 & 0.0017 & 0.0249 \\
$70-80$ & 0.0045 & 0.0017 & 0.0287 \\
$80-90$ & 0.0055 & 0.00408 & 0.0325 \\
$>90$ & 0.008 & 0.00408 & 0.0363 \\
\hline
\end{tabular}

This requires a model of the probability of occurrence of standreplacing fire in a particular stand under natural conditions (i.e., without the effect of fire suppression).

Murphy (1985) applies the methods of Van Wagner (1978) to estimate disturbance rates from inferred age-class distributions of Alberta's forests as of the years 1969, 1949, 1929, and 1909. He uses the disturbance rate as of 1949 to represent the presuppression disturbance rate. If one assumes that photo-interpreted age accurately represents years since disturbance and that the probability of a stand-replacing fire is independent of stand characteristics, the age class distribution can be described using a negative exponential probability density function. The parameter of the distribution represents the annual probability of any hectare in the forest being burnt by a stand-replacing fire. Based on the inferred age class distribution as of 1949 , Murphy estimates a fire probability for Alberta's northern forest of 0.0196 . We use a disturbance rate of 0.02 to approximate this pre-suppression rate in Scenario M2.

Using the inventory as of 1969, Murphy estimates a fire probability of 0.011 . In scenario M1, we approximate this with a burn rate of 0.01 . This rate is examined because it represents an intermediate level between Murphy's and Cumming's pre-suppression rates of disturbance. The fire return interval implied by the $1 \%$ disturbance rate also corresponds with the 100 -year return interval explicit in the sustained yield scenario.

Cumming (1997) develops his estimates of fire probability from maps of the areal extent of all known fires in his study area between the years 1940 and 1993. Based on statistical models of the types of stands burned in the years 1980 through 1993, he develops models of the composition of fires and, thus, stand type-specific disturbance rates. He uses a statistical model based on changes in the fire size distribution to correct for the effects of fire suppression. He differentiates between background years and event years, where event years are those years with extreme fire rates; the years 1940-1941 and 1980-1982 are the event years in Cumming's analysis. Fire events are assumed to occur every 30 years or so, and last an average of two to three years. Disturbance probabilities based on the conifer (specifically white spruce) content of stands are presented in Table 5. The average disturbance rates from this table are used in scenario $\mathrm{C} 1$.

\footnotetext{
${ }^{4}$ The sawtooth pattern apparent in these figures is due to the way volumes are assigned to the inventory. Volumes are tabulated by 10 -year age classes. In each year of the planning horizon, each inventory record is assigned a volume based on age rounded to the nearest decade, leading to jumps in volume disturbed.
} 

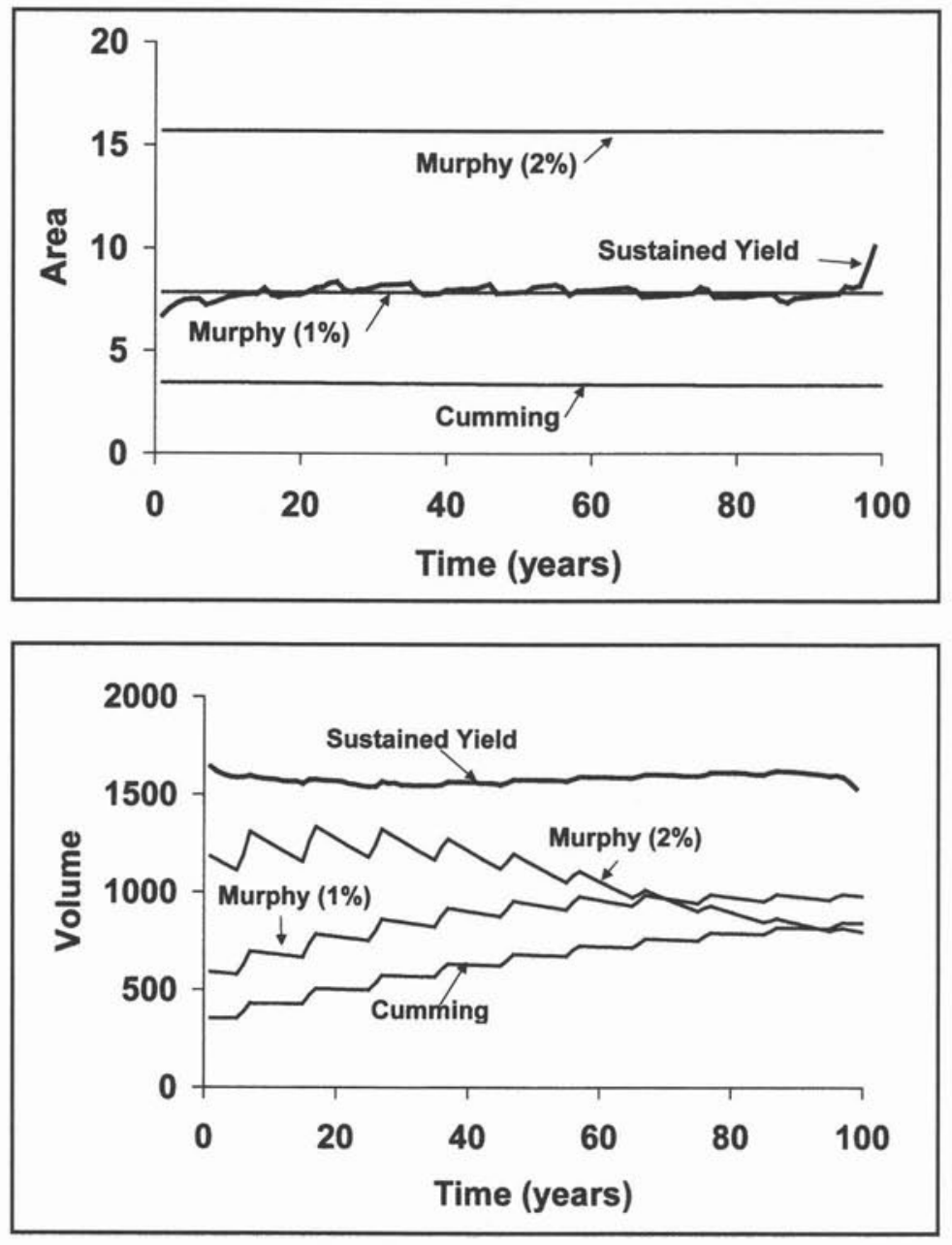

Fig. 1. Annual area disturbed $\left(10^{3} \mathrm{ha}\right)$ under each disturbance regime.

Fig. 2. Annual softwood volume disturbed $\left(10^{3} \mathrm{~m}^{3}\right)$ under each disturbance regime.

\section{Simulation Results}

The annual area disturbed under each of the four scenarios is presented in Fig. 1. In scenario M1, 7850 ha of forest is disturbed each year. In scenario M2, 15700 ha are disturbed each year. There is no variation in annual area disturbed under these scenarios because they assume constant rates of disturbance independent of forest composition or age-class structure. In scenario SY, the annual area disturbed closely approximates that in scenario M1, although there is some slight variation between years. In scenario $\mathrm{C} 1$, the annual area disturbed starts at about 3500 ha and declines very slightly over the 100 year planning horizon. The rate of disturbance for scenario $\mathrm{C} 1$ is less than half that in the other scenarios.

The softwood and hardwood volumes disturbed annually are presented in Figs. 2 and 3 respectively. ${ }^{4}$ Under the SY scenario, approximately $1.6 \times 10^{6} \mathrm{~m}^{3}$ of softwood $850 \times 10^{3} \mathrm{~m}^{3}$ of hardwood are disturbed each year of the planning horizon. Under the M1 scenario, between $600 \times 10^{3} \mathrm{~m}^{3}$ and $1.0 \times 10^{6}$ $\mathrm{m}^{3}$ of softwood and $400 \times 10^{3} \mathrm{~m}^{3}$ to $700 \times 10^{3} \mathrm{~m}^{3}$ of hardwood are disturbed annually. In scenario M2, the disturbed softwood volume decreases from $1.2 \times 10^{6} \mathrm{~m}^{3}$ to about $800 \times 10^{3} \mathrm{~m}^{3}$ over the planning horizon. The disturbed hardwood volume decreases $1.3 \times 10^{6} \mathrm{~m}^{3}$ to a low of about $550 \times 10^{3} \mathrm{~m}^{3}$. In scenario $\mathrm{C} 1$, the softwood volume disturbed increases from about $350 \times 10^{3} \mathrm{~m}^{3}$ to about $850 \times 10^{3} \mathrm{~m}^{3}$ over the planning horizon. The hardwood volume disturbed is nearly constant at about $200 \times 10^{3} \mathrm{~m}^{3}$.

Even though the annual areas disturbed under scenarios M1 and $\mathrm{SY}$ are similar, the volume disturbed in scenario M1 is about half that in SY. This occurs because in scenario SY area is scheduled for harvest on an oldest (i.e., highest volume) first basis, and in scenario M1 areas are disturbed proportionally across the age class distribution.

The average volume per hectare disturbed in each year of the planning horizon is presented in Fig. 4. For most of the planning horizon, an average of about $310 \mathrm{~m}^{3} \mathrm{ha}^{-1}$ is harvested under scenario SY. At the beginning of the planning horizon, nearly $370 \mathrm{~m}^{3} \mathrm{ha}^{-1}$ are disturbed; at the end, about $240 \mathrm{~m}^{3} \mathrm{ha}^{-1}$ are disturbed. These changes reflect the "rationing out" of overmature volume by the area-volume check procedure over the planning horizon. The $240 \mathrm{~m}^{3} \mathrm{ha}^{-1}$ disturbed at the end of the planning horizon is very near the long run average for this forest managed on a 100-year rotation. In scenario M1, the average volume disturbed is fairly stable over the planning horizon at about $180 \mathrm{~m}^{3} \mathrm{ha}^{-1}$. In scenario M2 the average volume disturbed declines from about $160 \mathrm{~m}^{3} \mathrm{ha}^{-1}$ to $90 \mathrm{~m}^{3} \mathrm{ha}^{-1}$. In scenario $\mathrm{C} 1$ the average volume disturbed increases from about 160 to about $300 \mathrm{~m}^{3} \mathrm{ha}^{-1}$ over the planning horizon. The increase in disturbed volume in scenario $\mathrm{C} 1$ is related to the small annual area disturbed; more of the forest gets a chance to age. 

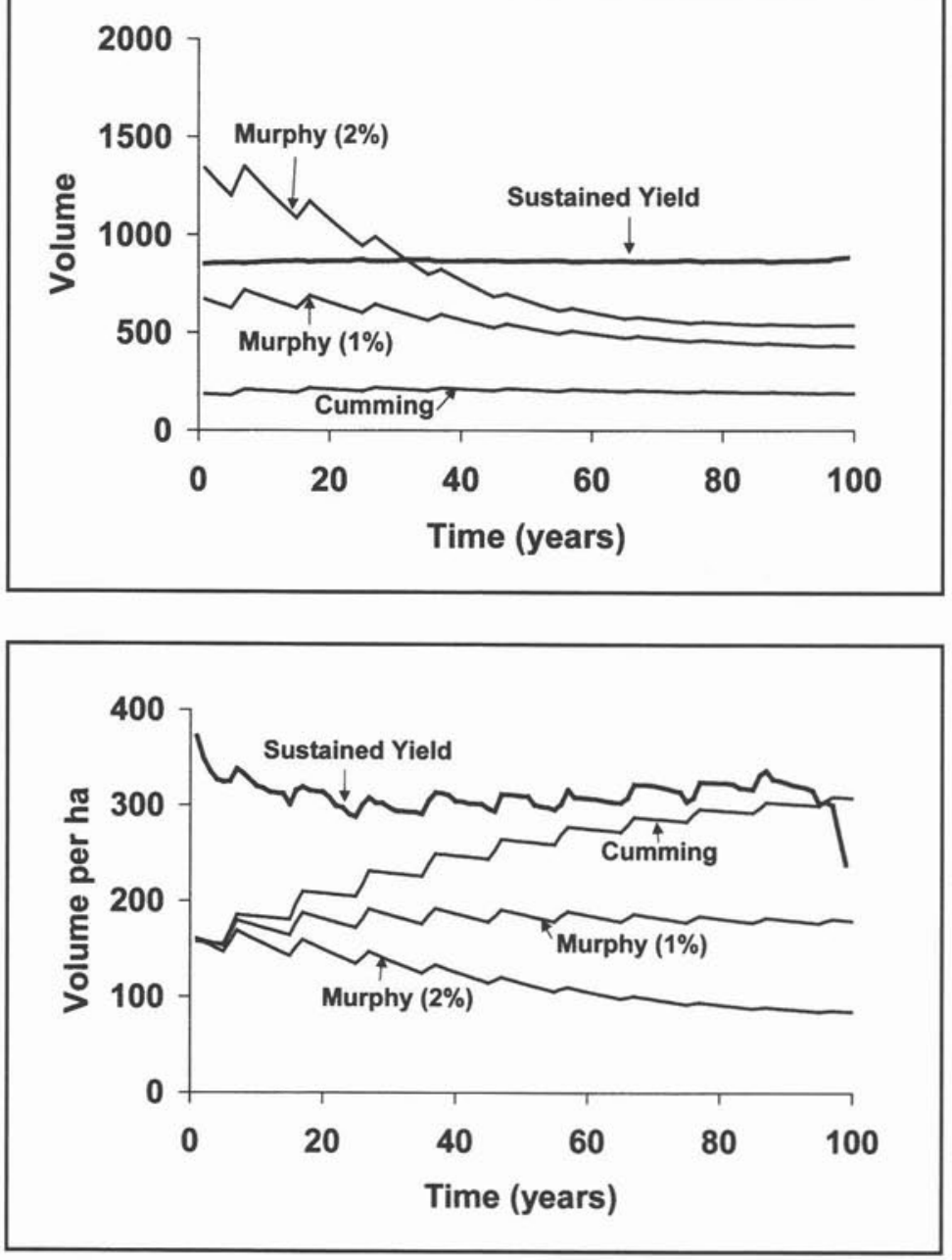

Fig. 3. Annual hardwood volume disturbed $\left(10^{3} \mathrm{~m}^{3}\right)$ under each disturbance regime.
Fig. 4. Average volume per hectare disturbed $\left(\mathrm{m}^{3} \mathrm{ha}^{-1}\right)$ under each disturbance regime.

\section{Discussion}

The results presented above provide some starting points for a discussion of natural disturbance management. There should not be too much weight placed on the numerical results: the important information is the relative magnitudes.

Perhaps the most striking differences in the results presented here are between the two pre-suppression natural disturbance regimes: Murphy's two percent model (scenario M2) and Cumming's conifer content specific model (scenario C1). The annual area disturbed in scenario M2 is 4.5 times as great as that disturbed in scenario $\mathrm{C} 1$. Given the differences in estimated disturbance rates, how does a manager decide which rate, if any, is appropriate for management? It could be that one of the rates is "more correct" than the other and that further investigation could help determine which is the appropriate rate. It is also possible that the mean rates reported by Cumming and Murphy are simply different outcomes of the same stochastic process. A recent simulation study conducted by Armstrong (1999) indicates that this could indeed be the case. In a Monte Carlo simulation of annual area burned, the mean area burnt from a pair of randomly generated 50 year series differed by a multiplicative factor of four, in one out of three draws.

If the rates proposed by Cumming are close to correct, many of the stands in the study area must be much older than is record- ed in the forest inventory. It is important to make the distinction between stand age and tree age. Stand age is the number of years between the most recent stand-replacing disturbance and the present time. Individual trees within a stand could have germinated or sprouted in the interim. The age recorded on the inventory records is determined through photo-interpretation, typically by estimating the height and the species of the canopy, assigning a site productivity class to the stand, and using height-age curves indexed by site class to stand age. The resulting estimate is more directly related to the age of the canopy trees than it is to the number of years since a stand-replacing event.

Divergence between photo-interpreted stand age and the number of years since a stand-replacing event could occur for a number of reasons. It is possible that white spruce could germinate in an aspen stand a number of years after the stand-replacing event. Through succession, white spruce could eventually dominate the stand. The photo-interpreted age of such a stand would reflect the age of the spruce trees, not accounting for the lag between stand initiation and spruce germination. Another possibility is that some aspen stands develop into uneven-aged stands through a process of gap phase dynamics (Shugart 1984). Again the photo-interpreted age would be based on the age of the canopy trees which would be in a continual state of replacement, resulting in an underestimate of stand age. 
Cumming (1995) presents some evidence that this occurs in the study area.

If Cumming's natural disturbance regime is approximately correct, the annual area disturbed would be 22 percent of that suggested by Murphy's natural disturbance regime, and about $45 \%$ of that scheduled under sustained yield management with a 100-year rotation. This clearly has some important timber supply implications, especially if forest tenures were allocated on the assumption of sustained yield management. In Alberta, most of the boreal forest has been allocated to industry through long term forest management agreements: there is little or no room to increase harvest levels in any part of the province given natural timber growth rates. Large-scale industrial development has occurred on the assumption of a timber supply level appropriate to sustained yield management. Would society be willing to pay for the perceived benefits of NDM management with a drop in harvestable area and economic activity of such magnitude? Alternatively, would society be willing to accept intensive management on part of the land base to make up the shortfall (if biologically possible and financially feasible)?

The effects of strict NDM management are even more pronounced when we consider annual harvest volume rather than annual harvest area. This occurs because in the sustained yield scenario, the oldest (and by our yield tables, highest volume) stands are disturbed first. In Murphy's characterization of natural disturbance, the disturbance rate is independent of age, so age classes are being disturbed in proportion to their representation in the inventory. This means that very young stands with no merchantable volume will be scheduled for disturbance. The effects of this show up in the lower average volumes per hectare disturbed (Fig. 4) under the natural disturbance scenarios.

This raises another important point. Nature would "schedule" some low volume, low value stands for disturbance. How important is it to emulate these "unprofitable" disturbances in a natural disturbance model? At the extreme, it may be desirable from an ecological point of view to deliberately burn or otherwise disturb some areas of immature forest in order to simulate the natural disturbance regime. This deliberate disturbance would be required to offset the reduction in fire rates due to fire suppression. Who should pay for the additional cost of these objectives? Timber harvest occurs only on the net productive land base. If the rate of disturbance on the non-productive area has been reduced through fire suppression efforts, should there be planned disturbances (e.g., prescribed burning) introduced to the unproductive land base?

Another characteristic of the natural fire regime is the variability in the disturbance rate from year to year. Given this variability, and assuming that the forest products industry requires some stability in the year-to-year flow of timber, which rate is the appropriate one on which to base management: the overall mean, the mean for background years, the mean for event years, or some other statistic (e.g., the median)? This becomes a risk-risk trade off decision. If one chooses too high a rate for timber harvest under a natural disturbance model, then some ecological benefits may not occur. If too low a rate is chosen, perhaps the risk of fire and severity of fires will increase, also reducing ecological benefits. Perhaps "the rate" is not an appropriate objective in any case: it is conceivable that the variability in annual area disturbed is as important ecologically as its average.
Given the difficulty in determining the average natural rate of disturbance, and the extreme year to year variability in the rate, the natural disturbance rate should not be the sole determinant of harvest rate. Other alternatives include variable rotation management strategies (Stelfox 1995), or using models which constrain the forest structure (defined, for example, by proportion of area within age class and spruce content) to fall within acceptable bounds (see, e.g., Cumming et al. 1994). "The rate" or some measure of risk/hazard should perhaps be an integral element in forest structure approaches and in determining the expected value of choices: it should not be the only objective of management.

As with any modelling exercise, the analysis presented here is a much-simplified representation of reality. The spatial elements of disturbance are ignored completely in this study, and may be worth examining. It is conceivable that timber harvest can mimic some forms of natural disturbance other than wildfire (e.g., windthrow, insect attack, gap dynamics), but these were not examined here. We have ignored management activities that may affect the probability of disturbance or growth rates (e.g., silviculture, changes in fire suppression strategy). Despite these omissions, we conclude that moving from sustained yield to natural disturbance models of forest management can have tremendous implications for the timber supply potential of an area, and that choosing the natural disturbance rate appropriate for a forest is both difficult and risky.

\section{Acknowledgements}

This research was funded by the Sustainable Forest Management Network. The authors gratefully acknowledge this financial support and the comments of Stan Boutin, Daryll Hebert, Jim Beck, Blair Hammond, Rick Pelletier, and Fiona Schmiegelow.

\section{References}

Alberta Forest Service. 1985. Alberta Phase 3 forest inventory: Yield tables for unmanaged stands. ENR Report Dept. 60a, Department of Energy and Natural Resources, Edmonton, Alberta.

Alberta Pacific Forest Industries Inc. undated. Environmental management. [web page]. <http://www.alpac.ca/regional.html> [Accessed 11 June 1998].

Armstrong, G. W. 1999. A stochastic characterisation of the natural disturbance regime of the boreal mixedwood forest with implications for sustainable forest management. Can. J. For. Res. 29: 424-433. Cumming, S. G. 1997. Landscape Dynamics of the Boreal Mixedwood Forest. Ph.D. dissertation, Department of Forest Sciences. University of British Columbia, Vancouver, BC.

Cumming, S. G., P. Burton, S. Prahacs, and M. Garland. 1994. Potential conflicts between timber supply and habitat protection in the boreal mixedwood of Alberta, Canada: A simulation study.

Forest Ecology and Management 68: 281-302.

Cumming, S. G., P. J. Burton, M. Joy, B. Klinkenberg, F. K. A. Schmiegelow, and J. N. M. Smith. 1995. Experimental habitat fragmentation and simulation of landscape dynamics in the boreal mixedwood: A pilot study. Canada-Alberta Partnership Agreement in Forestry Report A5016-137, Canadian Forest Service and the Alberta Land and Forest Service.

Davis, K. P. 1966. Forest Management: Regulation and Valuation, 2nd edition. McGraw-Hill Book Company, New York.

Gauthier, S., A. Leduc, and Y. Bergeron. 1996. Forest dynamics modelling under natural fire cycles: a tool to define natural mosaic diversity for forest management. Environmental Monitoring and Assessment (39): 417-434.

Haila, Y., I. K. Hanski, J. Niemelä, P. Punttila, S. Raivio, and H. 
Tukia. 1994. Forestry and the boreal fauna: matching management with natural dynamics. Ann. Zool. Fennici (31): 187-202.

Hunter, M. L. 1993. Natural fire regimes as spatial models for managing boreal forests. Biol. Conserv. (65): 115-120.

Johnson, E. A. 1992. Fire and Vegetation Dynamics: Studies from the North American Boreal Forest. Cambridge University Press.

Joy, M. W. 1995. Handling uncertainty in GIS and environmental models: an application in forest management. Master's thesis, Department of Geography, University of British Columbia, Vancouver, BC.

Lee, P. C., S. Crites, M. Neitfeld, H. V. Nguyen, and J. B. Stelfox. 1997. Characteristics and origins of deadwood material in aspendominated boreal forests. Ecological Applications (7): 691-701.

Murphy, P. J. 1985. Methods for Evaluating the Effects of Forest Fire Management in Alberta. Ph.D. dissertation, Department of Forestry. University of British Columbia, Vancouver, BC.
Reed, W. J. and D. Errico. 1986. Optimal harvest scheduling at the forest level in the presence of risk of fire. Can. J. For. Res. (16): 266-278. Shugart, H. H. 1984. A Theory of Forest Dynamics: The Ecological Implications of Forest Succession Models. Springer, New York. Stelfox, J. B. (ed.). 1995. Relationships between stand age, stand structure, and biodiversity in aspen mixedwood forests in Alberta. Jointly published by Alberta Environmental Centre (AECV95-R1), Vegreville Alberta and Canadian Forest Service (Project No. 0001a).

Van Wagner, C. E. 1978. Age-class distribution and the forest fire cycle. Can. J. For. Res. (8): 220-227.

Van Wagner, C. E. 1983. Simulating the effect of forest fire on longterm annual timber supply. Can. J. For. Res. (13): 451-457. 